\title{
低温熔融盐合成富磷相 $\mathrm{CuP}_{2}$ 纳米材料及其储锂应用
}

余学斌

复旦大学材料科学系, 上海 200433

\section{Synthesis of Phosphorous Rich $\mathrm{CuP}_{2}$ Nanostructure in Low Temperature Molten Salt and Its Lithium Storage Application}

\author{
Xuebin $\mathrm{Yu}$ \\ Department of Materials Science, Fudan University, Shanghai 200433, P. R. China. \\ Email: yuxuebin@fudan.edu.cn. \\ Published online: December 16, 2019.
}

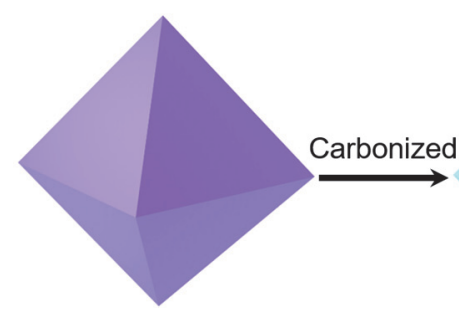

Cu MOF

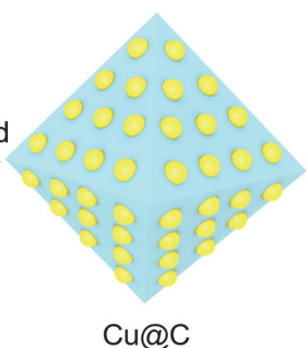

Cu@c

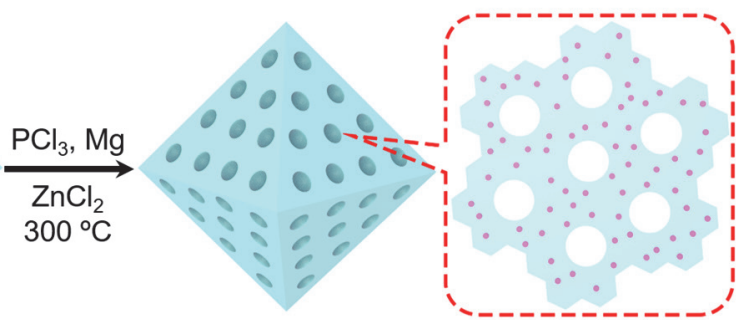

蜂巢状 $\mathrm{CuP}_{2} @ \mathrm{C}$ 的合成示意图。
纳米过渡金属磷化物 $\left(\mathrm{MP}_{x}, \mathrm{M}=\mathrm{Cu}, \mathrm{Ni}, \mathrm{Fe}\right.$, 等)在电催化, 光催化, 超级电容器以及锂离子电 池等领域具有很大的应用前景 $1-3$ 。在储锂应用中, 过渡金属磷化物的理论容量与磷的含量成正比, 因 此富磷的过渡金属磷化物最具吸引力。但目前富 磷 $\mathrm{MP}_{x}$ 的合成比较困难, 往往需要特殊的合成条 件。例如, 以正三辛基膦和 $\mathrm{CuCl}_{2}$ 为反应原料合成 $\mathrm{CuP}_{2}$ 纳米线, 需要利用超临界流体-液体-固体方 法, 在 $410{ }^{\circ} \mathrm{C}$ 和 $10.2 \mathrm{MPa}$ 的高温高压下反应 ${ }^{4}$; 而 以红磷作为磷源, 需要更高的温度合成富磷相过 渡金属磷化物 ${ }^{5-7}$, 并且该方法较难制备纯的富磷 相产物。

针对上述问题, 最近北京大学李星国教授和郑 捷副教授课题组开发了一种低温磷化方法, 在 $300{ }^{\circ} \mathrm{C}$ 的 $\mathrm{ZnCl}_{2}$ 熔融盐中, 利用 $\mathrm{Mg}$ 还原 $\mathrm{PCl}_{3}$ 实现磷 化。研究人员以 MOFs 衍生的 $\mathrm{Cu} @ \mathrm{C}$ 为起始原料, 合 成了具有蜂巢状特殊结构的 $\mathrm{CuP}_{2} @ \mathrm{C}$ 材料, 相关成 果近期发表在Angewandte Chemie International
Edition 上 $^{8}$ 。

低温熔融盐提供了特殊的反应环境。研究表 明, 真正起还原作用的是 $\mathrm{ZnCl}_{2}$ 被 $\mathrm{Mg}$ 还原产生的高 活性 $\mathrm{Zn}(0)$ 物种, 熔融盐中 $\mathrm{Zn}^{2+} / \mathrm{Zn}(0)$ 的可逆转化可 以实现了电子在熔融盐中的均匀分布, 将 $\mathrm{PCl}_{3}$ 还 原成高活性的 $\mathrm{P}$ 物种实现磷化。上述特点使得固相 反应物无需均匀混合, 亦能实现高效的完全磷化。 另外一个有趣的现象是熔融盐中发生了反常的 $\mathrm{Zn}^{2+}$ 氧化 $\mathrm{Cu}$ 的现象, 导致了 $\mathrm{Cu}$ 的溶解和迁移, 从 而形成了独特的蜂巢状结构。这一现象可能与 $\mathrm{Zn}$ 和 $\mathrm{Cu}$ 在高浓度 $\mathrm{Cl}^{-}$熔融盐中的稳定性相关, 值得进 一步深入研究。

制备得到的蜂巢状 $\mathrm{CuP}_{2} @ \mathrm{C}$ 具有优异的储锂性 能, 在 $0.2 \mathrm{~A} \cdot \mathrm{g}^{-1}$ 的电流下表现出 $1146 \mathrm{mAh} \cdot \mathrm{g}^{-1}$ 的高 可逆容量, 远高于葟磷的过渡金属磷化物, 充分体 现了富磷相在储锂中的优势; 此外蜂巢状的特殊 结构有利于 $\mathrm{Li}^{+}$和电子的快速传输, 因此 $\mathrm{CuP}_{2} @ \mathrm{C}$ 表现出良好的循环稳定性, 在 $1 \mathrm{~A} \cdot \mathrm{g}^{-1}$ 的电流下, 经 
过600次循环以后, 容量仍然稳定在 $720 \mathrm{mAh} \cdot \mathrm{g}^{-1}$, 且仍然保持蜂巢状的结构。

该工作发展了一种新型富磷相 $\mathrm{MP}_{x}$ 的合成方 法, 证明了富磷相 $\mathrm{MP}_{x}$ 在锂离子电池中应用的优 势, 同时表明低温熔融盐这一特殊反应介质在无 机纳米材料合成中具有巨大的潜力。该系列工作 得到了科技部国家重点研发计划和国家自然科学 基金委的经费支持。

\section{References}

(1) Xu, X.; Liu, J.; Liu, Z.; Wang, Z.; Hu, R.; Liu, J.; Ouyang, L.; Zhu, M. Small 2018, 14, 1800793. doi: 10.1002/smll.201800793

(2) Sun, H.; Xu, X.; Yan, Z.; Chen, X.; Cheng, F.; Weiss, P. S.; Chen, J. Chem. Mater. 2017, 29, 8539. doi: 10.1021/acs.chemmater.7b03627.
(3) Yang, Y.; Zhong, Y.; Shi, Q.; Wang, Z.; Sun, K.; Wang, H. Angew. Chem. Int. Ed. 2018, 57, 15549. doi: 10.1002/anie.201808311

(4) Li, G. A.; Wang, C. Y.; Chang, W. C.; Tuan, H. Y. ACS Nano 2016, 10, 8632. doi: 10.1021/acsnano.6b03954

(5) Lou, P.; Cui, Z.; Jia, Z.; Sun, J.; Tan, Y.; Guo, X. ACS Nano 2017, 11, 3705. doi: 10.1021/acsnano.6b08223

(6) Zhang, Y.; Wang, G.; Wang, L.; Tang, L.; Zhu, M.; Wu, C.; Dou, S. X.; Wu, M. Nano Lett. 2019, 19, 2575. doi: 10.1021/acs.nanolett.9b00342

(7) Chen, X.; Qiu, J.; Wang, Y.; Huang, F.; Peng, J.; Li, J.; Zhai, M. Electrochim. Acta 2018, 259, 321. doi: 10.1016/j.electacta.2017.10.186

(8) Liu, Z.; Yang, S.; Sun, B.; Yang, P.; Zheng, J.; Li, X. Angew. Chem. Int. Ed. 2020, 59, 1975. doi: 10.1002/anie.201910474 